International Journal of Child, Youth and Family Studies (2015) 6(4): 494-497

\title{
RESPONDING TO OUR CURRENT TIMES IN CHILD AND YOUTH CARE
}

\author{
Janet Newbury and Veronica Pacini-Ketchabaw
}

The 21st century is marked with a variety of unique and intersecting issues, opportunities, and political realities. Child and Youth Care (CYC) theory and practice continues to take place within and in response to a range of relationships, discourses, and institutions. Our relationship with the physical world is now understood with a sense of urgency as never before. Globalized economic systems are impacting how we organize on institutional and even interpersonal levels. Technologically mediated worlds are altering who we are, how we engage with each other, and how we envision and enact futures together. These pressing issues are often cast to the margins of CYC discussions, but are increasingly being experienced by many as central to the work we do and the lives we live.

Students, practitioners, and researchers had the opportunity to connect with each other, and with youth in the community and colleagues from across Canada and around the world, at the School of Child and Youth Care at the University of Victoria in British Columbia, Canada to discuss how to respond to our current times. CYC in Action IV: Responding to Our Current Times (May 1 to 3, 2014) was a lively conference that aimed to put Child and Youth Care practice into context, considering not only what we do and how we do it, but also the political, cultural, and economic conditions at play in our work.

Janet Newbury, Ph.D. is a sessional instructor at the School of Child and Youth Care, University of Victoria, P.O. Box 1700, STN CSC, Victoria B.C., Canada, V8W 2Y2. E-mail: newburyj@uvic.ca

Veronica Pacini-Ketchabaw, Ph.D. is a Professor in the School of Child and Youth Care at the University of Victoria, P.O. Box 1700, STN CSC, Victoria, British Columbia, Canada, V8W 2Y2. E-mail: vpacinik@uvic.ca 
Responding to Our Current Times was an opportunity to critically engage with these matters. It was a chance to explore diverse perspectives and experiences not only to help us better understand our current times, but also to consider how we might creatively engage with these realities. Together participants discussed research, practice, theory, and policy as they relate to children, youth, families, and communities. Some of the general themes of the conference included:

- $\quad$ Individual and collective healing: responsibilities and risks

- $\quad$ Economic, social, cultural, and political considerations

- $\quad$ Social justice and ethical praxis

- $\quad$ Queer and feminist perspectives on CYC research, practice, theory, and policy

- $\quad$ Conversations on decolonization

- $\quad$ Human service practices and the material world

- $\quad$ Solidarity, ally work, and friendship in CYC

- $\quad$ Contemporary child and youth care practices

The conference aimed to honour the diverse practices and ways of being that comprise this field as it continues to evolve in response to our times. Those who presented at the conference came wearing multiple hats, raising important considerations about residential care, early childhood education, counselling, research, intercultural practices, decolonizing practices, gender identities, diverse family compositions, mental health, diagnoses, youth justice, cyberspace, global conditions for children and youth, therapeutic relationships, music and art therapy, concepts and theories that guide our practice, mindfulness, organizational change, intercultural collaborations, advocacy, and so much more.

Importantly, these and other topics are understood not as distinct, but as interrelated by the very fact that they co-exist. Ron Barnett (2013) identifies these murky times as an era of "supercomplexity”. He notes that supercomplexity gives rise to

open-textured questions that yield, in a global and pluralist world, interpretations that are not just different but which are incompatible; and there is no straightforward way of resolving those differences. And this, in itself, marks off supercomplexity from complexity. Supercomplexity produces a multiplication of incompatible differences of interpretation. (p. 67)

The incompatible yet co-existing differences to which Barnett refers certainly presented themselves at the conference, and they are not likely to go away soon. Acknowledging supercomplexity changes our task from eliminating differences and determining "right” ways forward (in terms of practices, policies, or pedagogy), to "learning for an unknown future" (Barnett, 2013, p. 65). Since the multiplicities in which we find ourselves co-create our world through the ways they come together, he asserts that "the way forward lies in construing and enacting a pedagogy for human being ... an ontological turn ...” (p. 65, emphasis added).

It was in the spirit of inviting differences to interact that we organized CYC in Action IV: Responding to our Current Times. And it is in the same spirit that we put forward a call for conference presenters to submit articles to this special issue of the International Journal of 
International Journal of Child, Youth and Family Studies (2015) 6(4): 494-497

Child, Youth and Family Studies. Just as the conference sessions did not represent all that there is to the field, but rather offered a collection of possible entry-points, so too does this special issue refrain from making claims of representation. Instead, we invite you, as readers, to see this as a selection of important articles through which you can temporarily step into different areas of concern in Child and Youth Care, get a sense of its diversity, and imagine the ways these areas come together to create this evolving field of practice.

The first article is by Jennifer White, and is drawn from her keynote address at the conference. Recognizing that we are living in an era of constant change, she suggests that relying on fixed notions of right and ethical action might be getting us into trouble. How then might decisions be made and standards be determined when we acknowledge the power dynamics at play when doing so? In her article An Ethos for the Times, White challenges all of us to critically reflect on our own place in relation to the norms, discourses, and practices of our field, highlighting the complexities of ethical engagement. By engaging with our field on this macro level, she invites all of us to see our piece as part of what constitutes the whole. In so doing, she sets the tone for the remainder of this special issue, and raises important questions that can guide us in our reading throughout.

Patti Ranahan, Natasha Blanchet-Cohen, and Varda Mann-Feder take up some of these challenges as they consider how we educate for such a diverse and evolving field of practice. Taking as a case in point a graduate program in youth work at Concordia University in Montreal, Canada, the authors demonstrate how a range of practices and guiding principles are folded into their integrated approach to teaching and learning. Experiential activities, deep reflection, and critical engagement - even contradictory and competing conceptual frameworks - are thoughtfully incorporated into the curriculum. Moving Towards an Integrated Approach to Youth Work Education provides a glimpse into how youth workers are currently being prepared for such diverse roles as clinical counsellors, community outreach workers, and more.

It is crucial to understand that these macro discussions (and the decisions they inform) have very real implications for service delivery. The next article, by Alexandra Fleurie-Hunter, is entitled Exploring the Role of Agency Accreditation in Shaping Services for Street-involved Youth and invites us to do just that by considering one particular agency in Vancouver, Canada. Being exploratory in nature, the article outlines some of the developments in service provision for street-involved youth, importantly contextualizing these recent trends in policy development. In particular, it provides a more in-depth look at the move towards accreditation, reviewing literature from both its proponents and its critics. Through this, significant points for further inquiry are identified in order to contribute to a better understanding of the relationship between accreditation and service provision.

Shifting now from the vantage point of those who deliver services to that of some of the young people we strive to support, Victoria Namuggola's narrative study sheds important light on the day-to-day lives of domestic workers in Uganda. Critically engaging with the concept of "child labour", the voices of the young people she interviews call into question notions of autonomy, power dynamics, and freedom. This article, Exploitation or Empowerment? Adolescent Female Domestic Workers in Uganda, highlights some of the opportunities, challenges, and agency of so-called "house girls" and also recognizes the activities that take 
International Journal of Child, Youth and Family Studies (2015) 6(4): 494-497

place within households as critical components of the economies in which they take place (and of which they are a part).

In a contemporary analysis of capitalism, Kathleen Skott-Myhre and Hans Skott-Myhre propose to reconfigure notions of self-care, boundaries, professionalism, and more in child and youth care. In their article, Revolutionary Love: CYC and the Importance of Reclaiming our Desire, they suggest that the field of CYC might pay attention to what happens "between people, not within people”. Drawing on the work of Deleuze and Guattari, the authors engage with desire as an affective force rather than as a story of lack, and propose revolt through love.

The final article, The Canonical Self and Politicized Praxis: A Tracing of Two Concepts, also challenges child and youth care conceptualizations of the self. Scott Kouri provides a genealogical account of how "the self" has been mapped in the post-secondary child and youth care curriculum, and shows how these accounts of the self adhere to Western philosophical preoccupations with the individual. Kouri terms this treatment of the self in child and youth care as "the canonical self". The article ends with a call for alternative approaches that politicize the individualizing and essentializing canonical self.

\section{Reference}

Barnett, R. (2013). Learning for an unknown future. Higher Education Research and Development, 31(1), 65-77. http://dx.doi.org/10.1080/07294360.2012.642841 